\title{
Polo-like kinase 2 promotes chemoresistance and predicts limited survival benefit from adjuvant chemotherapy in colorectal cancer
}

\author{
YUQUAN XIE, YING LIU, QIUBO LI and JIANMING CHEN \\ Department of Oncology, The First People's Hospital of Jingmen City, Jingmen, Hubei 448000, P.R. China
}

Received November 8, 2017; Accepted February 2, 2018

DOI: $10.3892 / \mathrm{ijo} .2018 .4328$

\begin{abstract}
Colorectal cancer (CRC) is one of the most common malignances worldwide. Chemoresistance remains a major issue in the field of CRC treatment. The present study aimed to investigate the potential role of polo-like kinase 2 (Plk2) in chemoresistance in CRC. The associations between Plk2 and clinicopathological factors, as well as chemotherapeutic benefit were analyzed with a publicly available CRC dataset. The correlation between Plk2 expression and chemosensitivity was further confirmed in CRC cells. Moreover, knockdown and exogenous overexpression experiments of Plk2 were carried out to uncover the potential role of Plk2 in regulating the chemoresistance of CRC cells. We found that the expression of Plk2 was significantly associated with proximally located tumors. In addition, it was found that high expression ofPlk2 was associated with deficient mismatch repair status, B-raf serine/threonine kinase proto-oncogeneand Kirsten rat sarcoma viral oncogene homolog mutations. By contrast, tumor protein 53 mutation was correlated with a low expression level of Plk2. A higher expression level of Plk2 significantly predicted a poorer outcome in patients with CRC. However, the prognostic significance was only observed in patients who received adjuvant chemotherapy. In CRC cells, higher levels of Plk2 were associated with increased resistance to chemotherapeutic agents. Knocking down the expression of Plk2 resulted in elevated cellular apoptosis induced by oxaliplatin. By contrast, exogenous overexpression of Plk2 exerted an anti-apoptotic effect and enhanced the resistance of CRC cells to chemotherapeutic agents. In conclusion, a high
\end{abstract}

Correspondence to: Dr Jianming Chen, Department of Oncology, The First People's Hospital of Jingmen City, 67 Xiangshan Avenue, Jingmen, Hubei 448000, P.R. China

E-mail: chenjianming1999d@163.com

Abbreviations: Plk2, polo-like kinase 2; CRC, colorectal cancer; $\mathrm{dMMR}$, deficient mismatch repair; pMMR, proficient mismatch repair; GEO, Gene Expression Omnibus; OS, overall survival; DFS, disease-free survival; $\mathrm{IC}_{50}$, half maximal inhibitory concentration; FBS, fetal bovine serum; shRNA, short hairpin RNA

Key words: colorectal cancer, polo-like kinase 2, outcome, adjuvant chemotherapy, chemoresistance, apoptosis expression of Plk2 was associated with chemoresistant traits of CRC through inhibiting apoptosis. These results suggested that Plk2 may serve as a predictive marker for chemoresistance and a novel target in CRC treatment.

\section{Introduction}

Colorectal cancer (CRC) is the third most common malignancy among men and women in the United States (1). The 5-year survival rate for all patients with CRC was 65\%, from 2006 to 2012 (2). Tumor stage significantly affects patient outcome; the 5 -year survival rates for localized stage, regional and distant metastatic disease were 90, 71 and 14\%, from 2006 to 2012, respectively (2). Adjuvant chemotherapy has been demonstrated to improve the outcome of patients with CRC at the late-stage(3). However, the benefit of adjuvant chemotherapy in stage II CRC to survival is controversial (4-6). The mechanism underlying the resistance/sensitivity of CRC cells to chemotherapeutic agents remains to be fully elucidated. In addition, identifying novel predictive biomarkers may assist in predicting the clinical benefit of adjuvant chemotherapy for CRC.

To date, a series of genetic alterations have been identified in CRC. The deficient DNA mismatch repair (dMMR) feature is common in CRC, and is associated with clinical benefit from postoperative chemotherapy (7). The survival rates of patients with dMMR tumors were not improved by fluorouracil (5-Fu)-based adjuvant chemotherapy, compared with those with proficient mismatch repair (pMMR) tumors $(7,8)$. The Kirsten rat sarcoma viral oncogene homolog (KRAS) mutation occurs in $235-40 \%$ of CRC tumors $(9,10)$. An increased risk of recurrence is observed in CRC tumors with the KRAS mutation, compared with wild-type tumors (11). The B-raf serine/threonine kinase proto-oncogene (BRAF) mutation is preferentially observed in dMMR tumors, and is almost exclusive to the KRAS mutation in CRC (9). No significant difference in prognosis was reported between the BRAF mutation and wild-type tumors in stage II CRC (11), however, the BRAF mutation was associated with poor disease-free survival (DFS) rate of stage III CRC (12). Tumor protein 53 (TP53) is frequently mutated in several types of cancer, including CRC (13). It has been reported that TP53 mutations are more frequent in metastatic CRC, compared with primary CRC (14). However, evidence that mutations of the KRAS, BRAF or TP53 genes offer potential as a predictive marker for adjuvant chemotherapeutic benefit remains limited. 
The polo-like kinases (Plks), a family of serine/threonine protein kinases, are essential in cell cycle checkpoint and DNA damage signaling (15). Plk1 is essential for cell cycle regulation, and has been characterized with an oncogenic role in several types of cancer (16). However, the exact role of Plk2 in human cancer remains a topic of debate. A predominate suppression of the expression of Plk2 has been observed in B-cell lymphoma and ovarian cancer $(17,18)$. Plk2 inhibited cell proliferation and promoted chemotherapeutic drug-induced apoptosis in cervical cancer (19). Furthermore, a lower expression of Plk2 was associated with poor prognosis in breast cancer treated by irradiation (20). These observations suggested that Plk2 may serve as a tumor suppressor. Plk2 has been reported to be essential for promoting survival and inhibiting apoptosis in other cancer cells, including non-small cell lung cancer, head and neck carcinoma, and osteosarcoma (21-23). Previously, Ou et al reported that the protein levels of Plk2 were significantly elevated in tumor tissues, and were associated with adverse prognosis in CRC (24). These data suggested that the mechanism of Plk2 in carcinogenesis and cancer progression is more complex than previously expected. Whether Plk2 is involved in the chemoresistance of CRC remains to be fully elucidated.

In the present study, it was hypothesized that Plk2 is involved in the regulation of chemoresistance in CRC. By analyzing a public CRC dataset, it was found that a high expression of Plk2 was associated with dMMR, KRAS and BRAF mutations, and limited survival benefit for adjuvant chemotherapy in late stage CRC. In CRC cells, a higher expression of Plk2 was correlated with increased resistance to chemotherapeutic agents. Experiments involving the knockdown and exogenous overexpression of Plk2 demonstrated that this gene was involved in regulating the chemoresistance of CRC cells.

\section{Materials and methods}

Gene expression analysis of Plk2 in patients with CRC. The whole genome gene expression profile and clinical information of 566 CRC cases were collected from GSE39582 in the Gene Expression Omnibus (GEO, https://www.ncbi.nlm.nih. gov/geo/) (25). The dataset included 310 men and 256 women, with a median age of 69 years. Of these, 233 patients received standard adjuvant chemotherapy following surgical resection, 316 patients received surgical treatment alone; the treatment information for the remaining 17 patients was not available. The median follow-up time for DFS and overall survival (OS) were 3.58 and 4.25 years, respectively. For some patients in the cohort, we did not have DFS or OS information. The number of patients for which DFS and OS information was available was 560 and 562, respectively for the whole cohort. Similarly, in the adjuvant chemotherapy subgroup, DFS and OS information was available for 232 and 233 patients, respectively. In the mono-surgery treatment subgroup, DFS and OS information was available for 312 and 313 patients, respectively. The detailed clinical characteristics, adjuvant chemotherapy treatment and prognostic information were downloaded from the GEO website. The clinicopathological characteristics of the patients are summarized in Table I. The present study was a retrospective study and all data corresponding to the human tissues is publicly available in the GEO.
The gene expression data and the pharmacological data of certain anticancer drugs of CRC cell lines were also collected from the Cancer Cell Line Encyclopedia (CCLE) (26). The gene expression profiles of the CCLE (GSE36133) were downloaded from the GEO database.

The raw data of gene expression profiles ('cel' files of Affymetrix Human Genome U133 Plus 2.0 microarray) of the CRC samples or cell lines were downloaded from the GEO database. The gene expression profiles were $\log _{2}$-transformed and normalized with the 'RMA' method. 'PMA' callings were detected using the R package 'affy' (version 1.56.0, https://www. bioconductor.org/packages/release/bioc/html/affy.html). Probes that were characterized as 'Present' ('PMA' callings) in $>20 \%$ of the samples were retained. Probe annotation was performed based on the R package 'hgu133plus2.db' from Bioconductor (version 3.2.3, https://www.bioconductor.org/packages/release/ data/annotation/html/hgu133plus2.db.html). The gene expression value of Plk2 (probe set no. 201939_at) was extracted for subsequent analysis.

Cell culture and treatment. The SW620 cell line (cat. no. ATCC ${ }^{\circledR}$ CCL-227 ${ }^{\mathrm{TM}}$ ) and RKO cell line (cat. no. ATCC ${ }^{\circledR}$ CRL-2577 ${ }^{\mathrm{TM}}$ ) were purchased from the American Type Culture Collection (Manassas, VA, USA). The HT55 cell line (cat. no. 5061105) was purchased from the European Collection of Authenticated Cell Cultures (Sigma-Aldrich, St. Louis, MO, USA). The Colo-678 cell line (cat. no. ACC194) was purchased from the German Collection of Microorganisms and Cell Cultures (Leibniz Institute DSMZ, Braunschweig, Freistaat Sachsen, Germany). The cells were cultured in DMEM/F12 and RPMI-1640 medium with $10 \%$ fetal bovine serum (FBS) (Gibco/Thermo Fisher Scientific, Waltham, MA, USA), and incubated at $37^{\circ} \mathrm{C}$ with $5 \% \mathrm{CO}_{2}$. For the cell viability assay, the cells were seeded in 96 -well plates at $37^{\circ} \mathrm{C}$ at a density of $1.0 \times 10^{5} / \mathrm{ml}$, and treated with oxaliplatin or $5-\mathrm{Fu}$ at $0,4,2032$, $100,160,500$ and $800 \mathrm{nM}$ (6-wells/treatment) for $72 \mathrm{~h}$. Cell viability was detected with a Cell Counting kit-8 (CCK-8; Dojindo Molecular Technologies, Inc., Kumamoto, Japan) and the absorbance at $450 \mathrm{~nm}$ was recorded using the iMark microplate reader (Bio-Rad Laboratories, Inc., Hercules, CA, USA). Dose-response curves were fitted using the Sigmoid model. The half maximal inhibitory concentration $\left(\mathrm{IC}_{50}\right)$ was calculated by the fitted models.

Cells at $\sim 35 \%$ confluence were infected with a lentivirus packaging different plasmids, including Plk2 short hairpin RNA (shRNA), scramble control, Plk2 overexpression plasmids and vector control, and $10 \mu \mathrm{g} / \mathrm{ml}$ polybrene. After $24 \mathrm{~h}$, cells were selected with fresh media containing puromycin at $2 \mu \mathrm{g} / \mathrm{ml}$ for $48 \mathrm{~h}$. The cells were harvested and used for the cell viability assay as described above, western blot analysis and flow cytometric analysis. Lentiviral particles packaging the shRNA targeting Plk2 (5'-TAGTCAAGTGACGGTGCTG-3') and the scramble control (5'-TTCTCCGAACGTGTCACGT-3') were purchased from GeneChem Co., Ltd. (Shanghai, China). Lentiviral particles packaging the pGLV-PIk2 expression vector and the empty control vector were purchased from GenePharma Co., Ltd. (Shanghai, China).

Flow cytometric analysis. The cells were grown at $5 \times 10^{5} /$ well in 6-well plates overnight. The cells were then treated with 
Table I. Association between expression of Plk2 and clinical variables in colorectal cancer.

\begin{tabular}{|c|c|c|c|c|c|}
\hline \multirow[b]{2}{*}{ Variable } & \multirow[b]{2}{*}{ Parameter } & \multirow[b]{2}{*}{ All, n (\%) } & \multicolumn{2}{|c|}{ Expression of Plk2 } & \multirow[b]{2}{*}{ P-value } \\
\hline & & & Low, n (\%) & High, n (\%) & \\
\hline \multirow[t]{3}{*}{ Sex } & & & & & 0.447 \\
\hline & Female & $256(45.2)$ & $123(43.5)$ & $133(47)$ & \\
\hline & Male & $310(54.8)$ & $160(56.5)$ & $150(53)$ & \\
\hline \multirow[t]{3}{*}{ Age } & & & & & 0.064 \\
\hline & $<70$ years & $301(53.2)$ & $162(57.2)$ & 139 (49.1) & \\
\hline & $\geq 70$ years & $265(46.8)$ & $121(42.8)$ & $144(50.9)$ & \\
\hline \multirow[t]{3}{*}{ Tumor location } & & & & & $3.95 \times 10^{-7}$ \\
\hline & Distal & $342(60.4)$ & $201(71)$ & $141(49.8)$ & \\
\hline & Proximal & 224 (39.6) & $82(29)$ & $142(50.2)$ & \\
\hline \multirow[t]{7}{*}{ Stage } & & & & & 0.301 \\
\hline & CIS & $4(0.7)$ & $4(1.4)$ & $0(0)$ & \\
\hline & I & $37(6.5)$ & $20(7.1)$ & $17(6)$ & \\
\hline & II & $258(45.6)$ & $128(45.2)$ & $130(45.9)$ & \\
\hline & III & 203 (35.9) & $104(36.7)$ & $99(35)$ & \\
\hline & IV & $61(10.8)$ & $27(9.5)$ & 34 (12) & \\
\hline & NA & $3(0.5)$ & $0(0)$ & $3(1.1)$ & \\
\hline \multirow[t]{4}{*}{ MMR status } & & & & & $1.01 \times 10^{-8}$ \\
\hline & dMMR & 75 (13.3) & $15(5.3)$ & $60(21.2)$ & \\
\hline & pMMR & $444(78.4)$ & $251(88.7)$ & 193 (68.2) & \\
\hline & NA & 47 (8.3) & $17(6)$ & 30 (10.6) & \\
\hline \multirow[t]{4}{*}{ TP53 status } & & & & & $3.87 \times 10^{-7}$ \\
\hline & $\mathrm{Wt}$ & $161(28.4)$ & $57(20.1)$ & 104 (36.7) & \\
\hline & Mut & $190(33.6)$ & $120(42.4)$ & 70 (24.7) & \\
\hline & NA & $215(38)$ & $106(37.5)$ & $109(38.5)$ & \\
\hline \multirow[t]{4}{*}{ KRAS status } & & & & & 0.003 \\
\hline & $\mathrm{Wt}$ & $328(58)$ & $182(64.3)$ & $146(51.6)$ & \\
\hline & Mut & $217(38.3)$ & $91(32.2)$ & $126(44.5)$ & \\
\hline & NA & $21(3.7)$ & $10(3.5)$ & $11(3.9)$ & \\
\hline \multirow[t]{4}{*}{ BRAF status } & & & & & $5.24 \times 10^{-7}$ \\
\hline & Wt & 461 (81.4) & 248 (87.6) & $213(75.3)$ & \\
\hline & Mut & $51(9)$ & $8(2.8)$ & $43(15.2)$ & \\
\hline & NA & $54(9.5)$ & $27(9.5)$ & $27(9.5)$ & \\
\hline \multirow[t]{4}{*}{ Adj.Chem. } & & & & & 0.185 \\
\hline & No & $316(55.8)$ & $153(54.1)$ & 163 (57.6) & \\
\hline & Yes & $233(41.2)$ & $127(44.9)$ & $106(37.5)$ & \\
\hline & NA & $17(3)$ & $3(1.1)$ & $14(4.9)$ & \\
\hline
\end{tabular}

Plk2, polo-like kinase 2; MMR, mismatch repair; dMMR, deficient MMR; pMMR, proficient MMR; Wt, wild-type; Mut, mutation; KRAS, Kirsten rat sarcoma viral oncogene homolog; BRAF, B raf serine/threonine kinase proto oncogene; TP53, tumor protein 53; Adj.Chem., adjuvant chemotherapy; NA, not available.

oxaliplatin at $1 \mu \mathrm{M}$ (SW620 cells), or $4 \mu \mathrm{M}$ (Colo-678 cells), or dimethyl sulfoxide (DMSO) at a final concentration of $0.1 \%$ as a control for $16 \mathrm{~h}$. The cells were washed twice with phosphate-buffered saline. The cells were resuspended in binding buffer at $1 \times 10^{6}$ cells $/ \mathrm{ml}$. APC-conjugated Annexin V (5 $\mu \mathrm{l})$ and propidium iodide $(5 \mu \mathrm{l})$ were added to $100 \mu \mathrm{l}$ of cell suspension. The samples were incubated for $10 \mathrm{~min}$ at room temperature. Binding buffer $(400 \mu \mathrm{l})$ was added and the samples were analyzed using a BD FACSCanto II flow cytometer (BD Biosciences, Franklin Lakes, NJ, USA).

RNA extraction and reverse transcription-quantitative polymerase chain reaction ( $R T-q P C R)$ analysis. Total RNA from the $\mathrm{CRC}$ cell lines was isolated using an RNeasy Mini kit (Qiagen 
$\mathrm{GmbH}$, Düsseldorf, Germany), and then quantified using a NanoDrop 2000 spectrophotometer (Thermo Fisher Scientific, Inc., Waltham, MA, USA). The total RNA (100 ng) was subjected to RT-qPCR analysis with the iTaq Universal SYBR One-Step kit on the CFX-Connect Real-Time PCR detection system (both from Bio-Rad Laboratories, Inc., Hercules, CA, USA) following the manufacturer's instructions. The thermocycling conditions were as follows: $10 \mathrm{~min}$ at $50^{\circ} \mathrm{C}$ for reverse transcription reaction, $1 \mathrm{~min}$ at $95^{\circ} \mathrm{C}$ for polymerase activation and DNA denaturation (10 sec at $95^{\circ} \mathrm{C}$ for denaturation, $30 \mathrm{sec}$ at $60^{\circ} \mathrm{C}$ for annealing/extension and plate read) for 35 cycles, and a $0.5^{\circ} \mathrm{C}$ increment from 65 to $95^{\circ} \mathrm{C}$ for melt-curve analysis. The primers used were as follows: Plk2 forward, 5'-GCTGATGTCTGGCTGTTCAT CAG-3' and reverse sequence, 5'-CTTCCCTGTAGATCTCACA GTG-3'; GAPDH (endogenous control) forward, 5'-ACCCAG AAGACTGTGGATGG-3' and reverse sequence, 5'-TTCAGC TCAGGGATGACCTT-3'. The average quantification cycle $(\mathrm{Cq})$ of the triplicate experiments for each sample was used for the subsequent analysis. The gene expression was calculated using the $2^{-\Delta \Delta \mathrm{Cq}}$ method (27), where $\Delta \mathrm{Cq}=\mathrm{Cq}_{\text {target gene }}-\mathrm{Ct}_{\text {endogenous }}$, and $\Delta \Delta \mathrm{Cq}=\Delta \mathrm{Ct}_{\text {individual sample }}-\Delta \mathrm{Cq}_{\text {reference sample }}$.

Western blot analysis. The cells were lysed with cell lysis buffer (Cell Signaling Technology, Inc., Danvers, MA, USA) in the presence of protease inhibitors. Total protein $(40 \mu \mathrm{g})$ was electrophoresed on 12\% SDS-PAGE and electrophoretically transferred onto a PVDF membrane, and blocked with $5 \%$ skim milk at room temperature for $1 \mathrm{~h}$. The membranes were then probed with different primary antibodies overnight at $4^{\circ} \mathrm{C}$. The membranes were washed for 5 min three times in TBS with $0.1 \%$ Tween-20 and then incubated with horseradish peroxidase-conjugated mouse (1:10,000; cat. no. 1706516) or rabbit (1:10,000; cat. no. 1706515) (both from Bio-Rad, Laboratories, Inc.) secondary antibodies at room temperature for $1 \mathrm{~h}$. The membranes were washed 3 times for 5 min in TBS with $0.1 \%$ Tween-20, and then visualized with the Lumi-Light western blotting substrate (Roche Diagnostics, Basel, Switzerland) on the 5200 Chemiluminescence Imager (Tanon Science \& Technology Co., Ltd., Shanghai, China). The following primary antibodies were used: Mouse anti-Plk2 (1:1,000; cat. no. ab137539; Abcam, Cambridge, MA, USA), mouse anti-cleaved poly(ADP-ribose) polymerase-1 (PARP-1; 1:200; cat. no. sc56196; Santa Cruz Biotechnology, Inc., Dallas, TX, USA), mouse anti-GAPDH (1:5,000; cat. no. TA-08; ZSGB-BIO, Beijing, China).

Statistical analysis. All patients with CRC were grouped into Plk2-low and Plk2-high expression subgroups by the median Plk2 expression value. The association between Plk2 subgroups and the clinical/genetic variables was tested using Pearson's $\chi^{2}$ test with Yates' continuity correction or Fisher's exact test. The Kaplan-Meier curve was applied to compare the DFS and OS of patients between different Plk2 subgroups, and the log-rank test was used to estimate the significance. Cox's univariate proportional hazards model was used for Plk2 subgroups and different clinical variables, based on the DFS and OS. Multivariate Cox analysis was performed for all clinical variables initially. The final model was selected by a stepwise selection process with the Akaike information criterion. To analyze the clinical benefit of adjuvant chemotherapy, the Kaplan-Meier curve and log-rank test were performed for DFS and OS between patients with and without adjuvant chemotherapy. The P-value of the RT-qPCR data of the four cell lines was calculated using one-way analysis of variance and multiple comparisons using Tukey's 'Honest Significant Difference' method. The difference in cell apoptotic rate, determined by flow cytometry, was calculated using Student's t-test (unpaired). All of these statistical tests were two-sided, and performed using $\mathrm{R}$ software (version 3.3.0, https://www.r-project.org/). $\mathrm{P}<0.05$ was considered to indicate a statistically significant difference.

\section{Results}

Association between the expression of Plk2 and clinical/ genetic parameters in patients with CRC. The present study investigated the association between the gene expression of Plk2 and clinical or genetic variables in the CRC cohort. As shown in Table I, a high expression of Plk2 was significantly correlated with the proximal location of tumors $\left(\mathrm{P}=3.95 \times 10^{-7}\right)$. A significant association was also found between the high expression of Plk2 and dMMR $\left(\mathrm{P}=1.0 \times 10^{-8}\right)$, wild-type TP53 $\left(\mathrm{P}=3.87 \times 10^{-7}\right)$, mutant KRAS $(\mathrm{P}=0.003)$ and mutant BRAF $\left(\mathrm{P}=5.24 \times 10^{-7}\right)$. There was a trend of significance between the expression of $\mathrm{Plk} 2$ and patient age $(\mathrm{P}=0.064)$. No statistically significant association was found between the expression of Plk2 and sex $(\mathrm{P}=0.447)$ or tumor-node-metastasis stage $(\mathrm{P}=0.301)$. There was also no statistically significant difference in the expression of Plk2 between patients who received adjuvant chemotherapy and those who did not receive adjuvant chemotherapy $(\mathrm{P}=0.185)$.

Prognostic value of Plk2 in patients with CRC who received adjuvant chemotherapy. To evaluate the prognostic value of Plk2, all patients were grouped into Plk2-high and Plk2-low subgroups by the median expression value. Kaplan-Meier analysis revealed that patients with a high expression of Plk2 had a poorer DFS, compared with those with a low expression (log-rank test, $\mathrm{P}=7.0 \times 10^{-4}$ ) (Fig. 1, upper left). Additionally, a high expression of Plk2 was associated with a shorter OS (log-rank test, $\mathrm{P}=0.031$ ) (Fig. 1, upper right). However, the prognostic significance of Plk2 was not observed in the subgroup of patients who did not receive adjuvant chemotherapy, based on either DFS or OS (log-rank test, P>0.1) (Fig. 1, middle panel). When the patients who received adjuvant chemotherapy were analyzed, a high expression of Plk2 was significantly correlated with poorer DFS (log-rank test, $\mathrm{P}=1.8 \times 10^{-5}$ ) (Fig. 1, bottom left) and shorter OS (log-rank test, $\mathrm{P}=0.002$ ) (Fig. 1, bottom right), respectively.

Subsequently, the present study investigated whether Plk2 was an independent prognostic factor in patients with CRC who received adjuvant chemotherapy. For DFS (Table II), stage IV $(\mathrm{HR}=3.81,95 \% \mathrm{CI}: 1.89-7.71, \mathrm{P}=0.0002)$ and a high expression of Plk2 (HR=2.46, 95\% CI: $\left.1.61-3.76, \mathrm{P}=3.3 \times 10^{-5}\right)$ were significant prognostic factors, according to univariate Cox analysis. The multivariate Cox model showed that a high expression of Plk2 ( $\mathrm{HR}=3.18,95 \% \mathrm{CI}$ : 1.88-5.35, $\left.\mathrm{P}=1.43 \times 10^{-5}\right)$ was an independent prognostic factor for DFS (Table II). Additionally, univariate Cox analysis revealed that stage IV $\left(\mathrm{HR}=9.4,95 \% \mathrm{CI}: 4.58-19.29, \mathrm{P}=1.0 \times 10^{-9}\right)$, mutant KRAS 
Table II. Cox proportional hazards regression for DFS of patients with colorectal cancer who received adjuvant chemotherapy.

\begin{tabular}{|c|c|c|c|c|c|}
\hline \multirow[b]{2}{*}{ Variable } & \multirow[b]{2}{*}{ Parameter } & \multicolumn{2}{|c|}{ Univariate Cox } & \multicolumn{2}{|c|}{ Multivariate Cox } \\
\hline & & HR $(95 \%$ CI $)$ & P-value & HR $(95 \%$ CI $)$ & P-value \\
\hline \multirow[t]{2}{*}{ Sex } & Female & 1 & & & \\
\hline & Male & $1.01(0.67-1.53)$ & 0.959 & & \\
\hline \multirow[t]{2}{*}{ Age } & $<70$ years & 1 & & & \\
\hline & $\geq 70$ years & $0.91(0.57-1.43)$ & 0.669 & $0.60(0.32-1.12)$ & 0.111 \\
\hline \multirow[t]{2}{*}{ Tumor location } & Distal & 1 & & & \\
\hline & Proximal & $0.68(0.43-1.08)$ & 0.104 & $0.56(0.31-1.01)$ & 0.055 \\
\hline \multirow[t]{3}{*}{ Stage } & II & 1 & & 1 & \\
\hline & III & $1.32(0.78-2.25)$ & 0.304 & $1.61(0.84-3.12)$ & 0.154 \\
\hline & IV & $3.81(1.89-7.71)$ & $2.0 \times 10^{-4}$ & $4.67(2.02-10.81)$ & $3.1 \times 10^{-4}$ \\
\hline \multirow[t]{2}{*}{ MMR status } & pMMR & 1 & & & \\
\hline & $\mathrm{dMMR}$ & $0.67(0.25-1.84)$ & 0.441 & $0.30(0.07-1.26)$ & 0.101 \\
\hline \multirow[t]{2}{*}{ TP53 status } & $\mathrm{Wt}$ & 1 & & & \\
\hline & Mut & $1.10(0.62-1.95)$ & 0.736 & & \\
\hline \multirow[t]{2}{*}{ KRAS status } & $\mathrm{Wt}$ & & & & \\
\hline & Mut & $1.27(0.82-1.96)$ & 0.278 & & \\
\hline \multirow[t]{2}{*}{ BRAF status } & $\mathrm{Wt}$ & 1 & & & \\
\hline & Mut & $0.60(0.15-2.45)$ & 0.476 & & \\
\hline \multirow[t]{2}{*}{ Expression of Plk2 } & Low & 1 & & 1 & \\
\hline & High & $2.46(1.61-3.76)$ & $3.27 \times 10^{-5}$ & $3.18(1.88-5.35)$ & $1.43 \times 10^{-5}$ \\
\hline
\end{tabular}

$(\mathrm{HR}=1.86,95 \% \mathrm{CI}: 1.17-2.97, \mathrm{P}=0.009)$ and a high expression of Plk2 (HR=2.07, 95\% CI: 1.31-3.29, $\mathrm{P}=0.002)$ were high risk factors for poor OS (Table III).Multivariate analysis showed that a high expression of $\mathrm{Plk} 2(\mathrm{HR}=1.75,95 \% \mathrm{CI}: 1.08-2.84$, $\mathrm{P}=0.024$ ) was an independent prognostic factor for $\mathrm{OS}$ in the final model (Table III).

Plk2 as a potential predictor of survival benefit from adjuvant chemotherapy for late stage CRC. Adjuvant chemotherapy was routinely used for the majority of the late stage CRC cases. The present study aimed to determine whether the expression of Plk2 affects the survival benefit of adjuvant chemotherapy in stage III/IV CRC. For all patients with stage III/IVCRC, adjuvant chemotherapy did not improve DFS in this cohort (log-rank test, $\mathrm{P}=0.52$, Fig. 2A, upper left panel). A trend of improved DFS for adjuvant chemotherapy was observed in the Plk2-low subgroup (log-rank test, $\mathrm{P}=0.14$, Fig. 2A, upper middle panel), but not in the Plk2-high subgroup (log-rank test, $\mathrm{P}=0.41$ ) (Fig. 2A, upper right panel). For OS, patients who received adjuvant chemotherapy had significantly improved prognosis, compared with those without adjuvant chemotherapy when considering all stage III/IV patients (log-rank test, $\mathrm{P}=0.0009$ ) (Fig. 2A, bottom left panel) or the Plk2-low subgroup (log-rank test, $\mathrm{P}=0.001$ ) (Fig. $2 \mathrm{~A}$, bottom middle panel). However, adjuvant chemotherapy did not significantly improve $\mathrm{OS}$ in the Plk2-high subgroup (log-rank test, $\mathrm{P}=0.18$ ) (Fig. 2A, bottom right panel). The dMMR status is associated with limited chemotherapeutic benefit in CRC. The present study evaluated the survival effect of Plk2 in the sub-population with pMMR, which included the majority of the patients. Similarly, the survival benefit from adjuvant chemotherapy was preferentially observed in patients with tumors expressing a low level of Plk2 (Fig. 2B). These data suggested that a high expression of Plk2 may be associated with limited clinical benefit from adjuvant chemotherapy in late stage CRC. In addition, the association may be independent of MMR status.

High expression of Plk2 is associated with low sensitivity to chemotherapeutic agents in CRC cells. To examine the association between Plk2 and chemotherapy, the present study detected the expression levels of Plk 2 in four CRC cell lines. The mRNA level of Plk2 was significantly higher in the HT-55 and Colo-678 cells, compared with that in the SW620 and RKO cells (Fig. 3A). In addition, western blot analysis showed elevated protein levels of Plk2 in the HT-55 and Colo-678 cells, compared with levels in the SW620 and RKO cells (Fig. 3B). The cell viability assay revealed that $\mathrm{IC}_{50}$ values to oxaliplatin for the HT-55, Colo-678, SW620 and RKO cells were $7.32 \mu \mathrm{M}$ (95\% CI: 6.5-8.25), $26.4 \mu \mathrm{M}$ (95\% CI: 24.1-28.91), $1.22 \mu \mathrm{M}(95 \% \mathrm{CI}: 1.07-1.4)$ and $2.0 \mu \mathrm{M}(95 \% \mathrm{CI}: 1.67-2.39)$, 

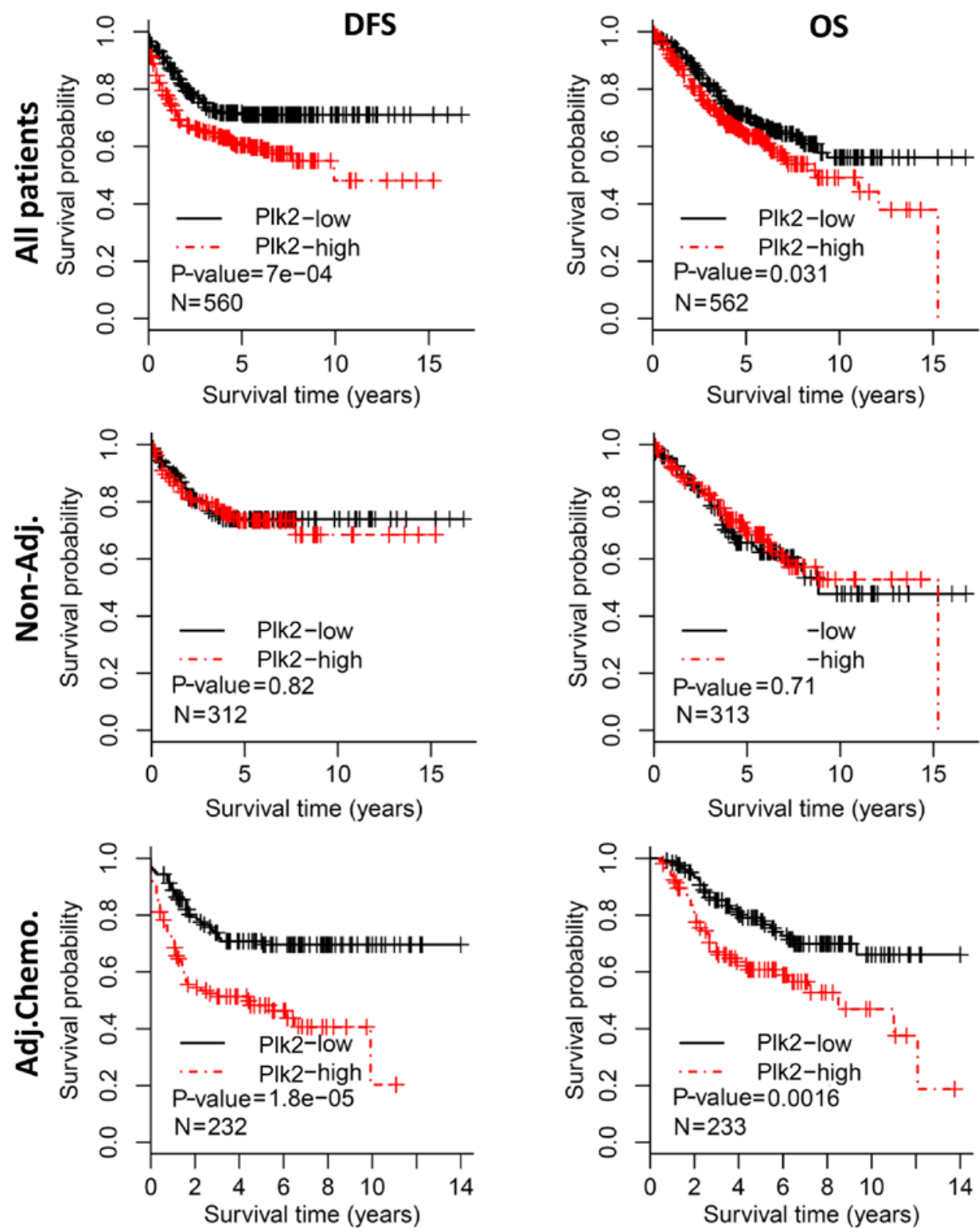

Figure 1. Survival analysis of the expression of Plk2 in patients withcolorectal cancer. All patients were divided into Plk2-low and Plk2-high subgroups by the median expression levels of Plk2. Kaplan-Meier curves showed the survival differences of Plk2 subgroups based on DFS (left column) and OS (right column). Survival analysis was performed in all patients (upper panel), patients without adjuvant chemotherapy (middle panel) and patients who received adjuvant chemotherapy (bottom panel), respectively. The P-value was calculated by the log-rank test. Plk2, polo-like kinase 2; DFS, disease-free survival; OS, overall survival; non-Adj., without adjuvant chemotherapy; Adj.Chemo., with adjuvant chemotherapy.

respectively (Fig. $3 \mathrm{C}$ ). Accordingly, the $\mathrm{IC}_{50}$ values to $5-\mathrm{Fu}$, another chemotherapeutic agent used in CRC treatment, for the HT-55, Colo-678, SW620 and RKO cells were $38.85 \mu \mathrm{M}$ (95\% CI: 32.51-46.42), 54.81 $\mu \mathrm{M}$ (95\% CI: 46.36-64.8), $5.55 \mu \mathrm{M}$ (95\% CI: 4.68-6.58) and 3.63 $\mu \mathrm{M}$ (95\% CI: 2.77-4.77), respectively (Fig. 3D). These findings were confirmed using the CCLE dataset. Consistent with the results of the RT-qPCR analysis, the mRNA level of Plk2 was higher in the Colo-678 and HT-55 cells, compared with that in the SW620 and RKO cells in the microarray (Fig. 3E). The pharmacological results indicated that Colo-678 cells were more resistant to certain chemotherapeutic agents, compared with the SW620 and RKO cells (Fig. 3F). The pharmacological results of the HT-55 cell line were not available in the CCLE database. These data suggested that a higher expression level of Plk2 was associated with increased resistance to chemotherapeutic agents in the CRC cells.

Plk2 contributes to anti-apoptosis and chemoresistance in CRC cells. Subsequently, the present study examined whether the dysregulation of Plk2 affects chemoresistance in CRC cells. The Colo- 678 cells were infected with lentivirus-encoded scramble or Plk2 shRNA for $48 \mathrm{~h}$ to deplete the expression of Plk2. The Colo-678 cells expressing Plk2-shRNA exhibited decreased $\mathrm{IC}_{50}$ to oxaliplatin (shRNA, vs. scramble, $4.57 \mu \mathrm{M}$, 95\% CI: 4.03-5.18, vs. $23.11 \mu \mathrm{M}, 95 \%$ CI: $21.41-24.95)$ and decreased $\mathrm{IC}_{50}$ to 5 -Fu (shRNA, vs. scramble, $9.69 \mu \mathrm{M}$, 95\% CI: 8.43-11.13, vs. $48.02 \mu \mathrm{M}, 95 \%$ CI: 41.1-56.11), as shown in Fig. 4A and B. Similarly, the sensitivity to oxaliplatin of the HT55 cells was increased when the expression of Plk2 was 
A
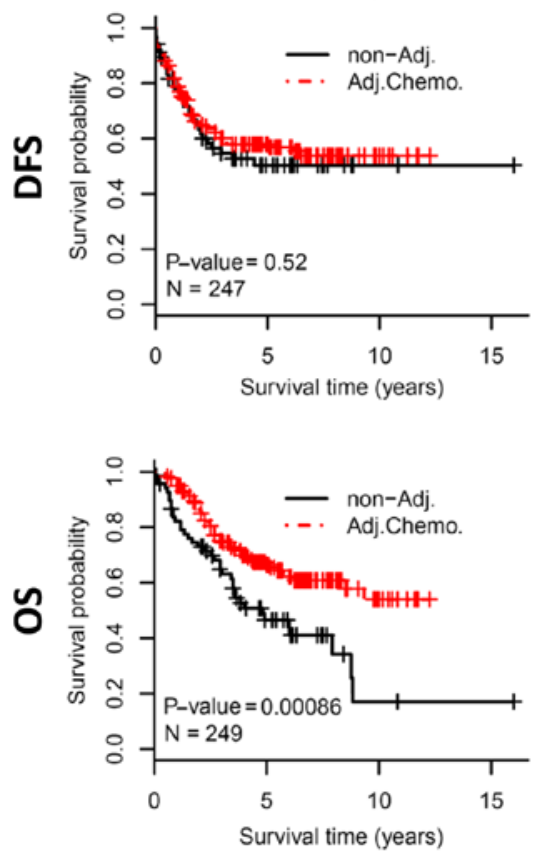

B
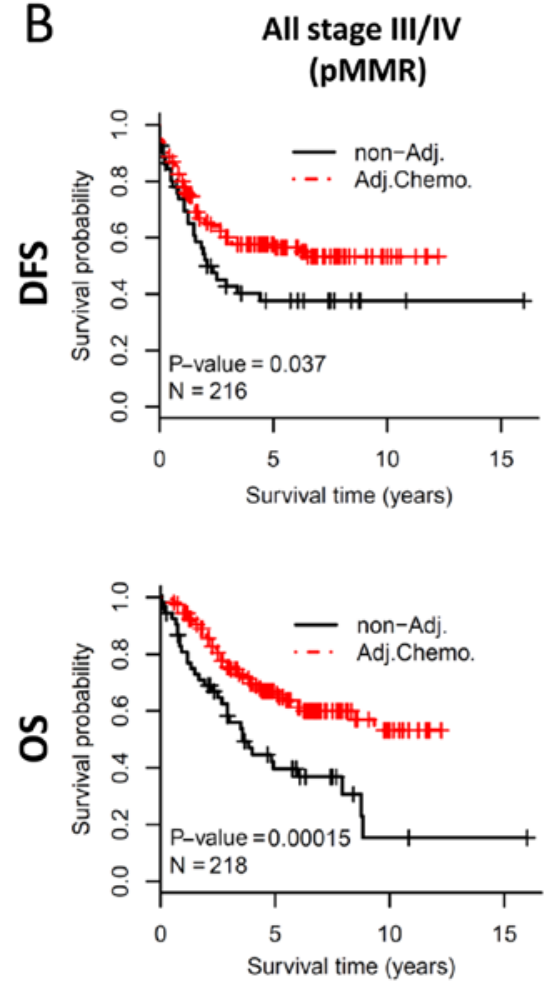

Plk2-low
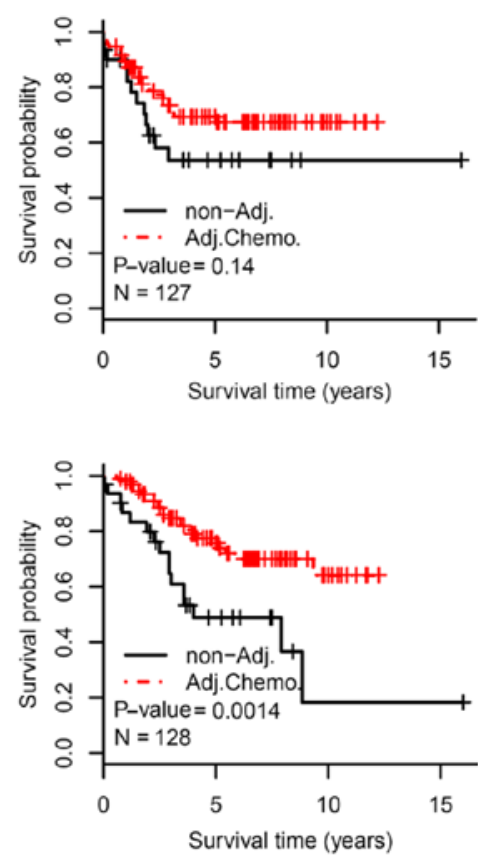

PIk2-low (pMMR)
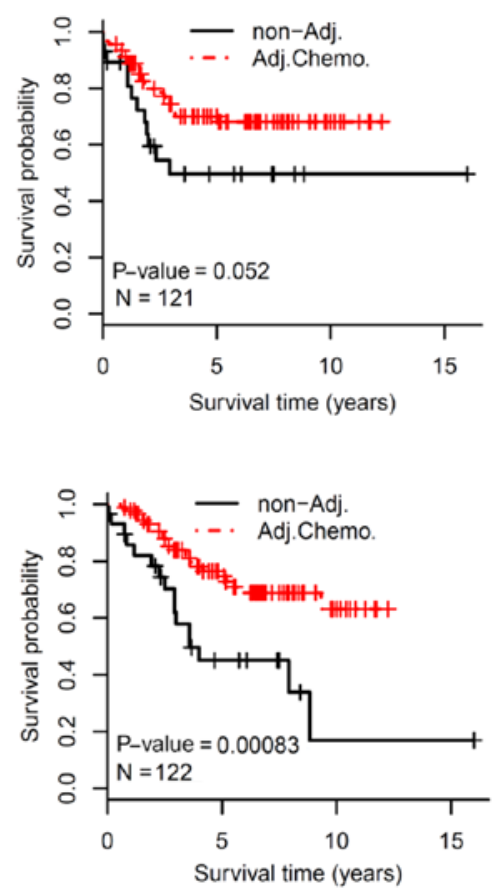

Plk2-high
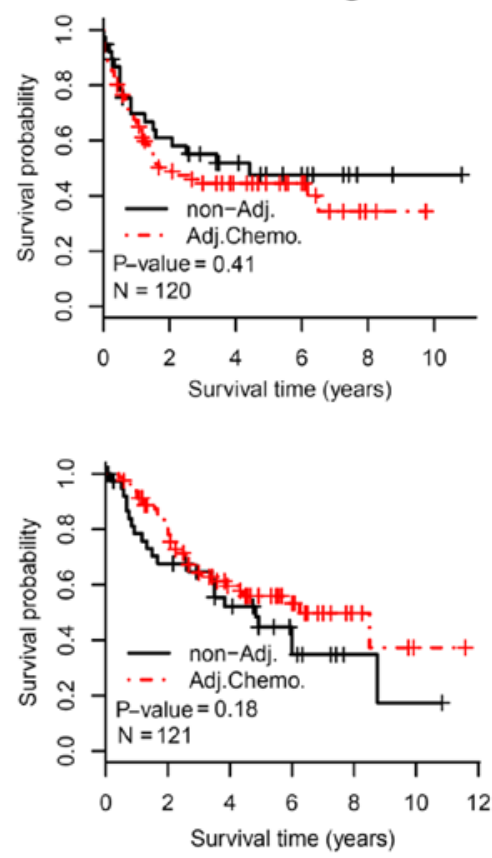

PIk2-high

(pMMR)
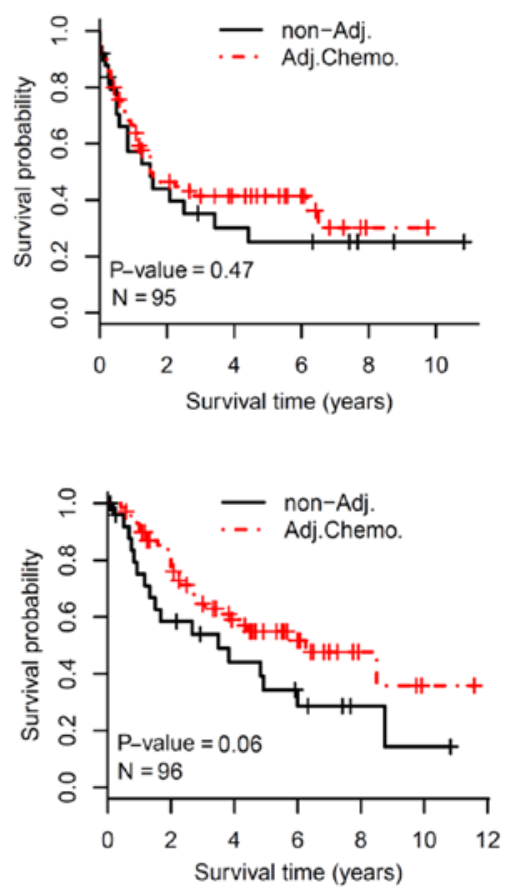

Figure 2. Survival benefit of adjuvant chemotherapy in late stage colorectal cancer. The results of (A) all stage III/IV patients and (B) all stage III/IV patients with pMMR status are shown. All patients (left column), the Plk2-low subgroup (middle column) and the Plk2-high subgroup (right column) were analyzed. The upper and lower panels show DFS and OS benefit from adjuvant chemotherapy respectively. The Kaplan-Meier curves show DFS/OS differences in patients with or without adjuvant chemotherapy. The P-value is calculated by the log-rank test. Plk2, polo-like kinase 2; DFS, disease-free survival; OS, overall survival; non-Adj., without adjuvant chemotherapy; Adj.Chemo., with adjuvant chemotherapy; pMMR, proficient mismatch repair.

depleted by shRNA (Fig. 4C, $\mathrm{IC}_{50}$ Plk2-shRNA, vs. scramble, $2.0 \mu \mathrm{M}, 95 \%$ CI: 1.8-2.24, vs. $6.82 \mu \mathrm{M}, 95 \%$ CI: 6.05-7.69). Western blot analysis demonstrated a marked decrease in the protein level of Plk2 in the Plk2-shRNA cells (Fig. 4D). In addition, an apoptotic assay was performed to determine whether the decrease in the expression of Plk2 led to increased apoptosis in response to chemotherapeutic agents. As shown in Fig. 4E, following treatment with $4 \mu \mathrm{M}$ oxaliplatin for $16 \mathrm{~h}$, the scramble cells did not show increased levels of cleaved PARP (a marker of apoptosis). However, oxaliplatin treatment induced a significant elevation of cleaved PARP in the Plk2-knockdown cells. Flow cytometric analysis showed that Colo-678 cells with Plk2 
Table III. Cox proportional hazards regression for OS of patients with colorectal carcinoma who received adjuvant chemotherapy.

\begin{tabular}{|c|c|c|c|c|c|}
\hline \multirow[b]{2}{*}{ Variable } & \multirow[b]{2}{*}{ Parameter } & \multicolumn{2}{|c|}{ Univariate Cox } & \multicolumn{2}{|c|}{ Multivariate Cox } \\
\hline & & HR (95\% CI) & P-value & $\mathrm{HR}(95 \% \mathrm{CI})$ & P-value \\
\hline \multirow[t]{2}{*}{ Sex } & Female & 1 & & & \\
\hline & Male & $1.22(0.77-1.94)$ & 0.397 & & \\
\hline \multirow[t]{2}{*}{ Age } & $<70$ years & 1 & & & \\
\hline & $\geq 70$ years & $1.18(0.72-1.93)$ & 0.504 & & \\
\hline \multirow[t]{2}{*}{ Tumor location } & Distal & 1 & & & \\
\hline & Proximal & $1.31(0.81-2.1)$ & 0.271 & & \\
\hline \multirow[t]{3}{*}{ Stage } & II & 1 & & 1 & \\
\hline & III & $1.14(0.63-2.06)$ & 0.675 & $1.07(0.58-1.98)$ & 0.819 \\
\hline & IV & $9.40(4.58-19.29)$ & $1.04 \times 10^{-9}$ & $9.75(4.66-20.39)$ & $1.48 \times 10^{-9}$ \\
\hline \multirow[t]{2}{*}{ MMR status } & pMMR & 1 & & & \\
\hline & dMMR & $0.94(0.34-2.59)$ & 0.906 & & \\
\hline \multirow[t]{2}{*}{ TP53 status } & $\mathrm{Wt}$ & 1 & & & \\
\hline & Mut & $1.06(0.56-2.02)$ & 0.852 & & \\
\hline \multirow[t]{2}{*}{ KRAS status } & $\mathrm{Wt}$ & 1 & & 1 & \\
\hline & Mut & $1.86(1.17-2.97)$ & 0.009 & $1.71(1.06-2.76)$ & 0.029 \\
\hline \multirow[t]{2}{*}{ BRAF status } & $\mathrm{Wt}$ & 1 & & & \\
\hline & Mut & $0.38(0.05-2.73)$ & 0.335 & & \\
\hline \multirow[t]{2}{*}{ Expression of Plk2 } & Low & 1 & & 1 & \\
\hline & High & $2.07(1.31-3.29)$ & 0.002 & $1.75(1.08-2.84)$ & 0.024 \\
\hline
\end{tabular}

Table IV. Univariate Cox proportional hazards regression analysis of Plk family in patients with colorectal cancer.

\begin{tabular}{|c|c|c|c|c|c|}
\hline \multirow[b]{2}{*}{ Patient group } & \multirow[b]{2}{*}{ Plk family } & \multicolumn{2}{|c|}{ DFS } & \multicolumn{2}{|c|}{ OS } \\
\hline & & HR $(95 \%$ CI $)$ & P-value & HR $(95 \%$ CI $)$ & P-value \\
\hline \multirow[t]{4}{*}{ All } & Plk1 (high vs. low) & $0.65(0.48-0.87)$ & 0.004 & $0.66(0.5-0.88)$ & 0.005 \\
\hline & Plk2 (high vs. low) & $1.68(1.24-2.27)$ & 0.0008 & $1.37(1.03-1.82)$ & 0.032 \\
\hline & Plk3 (high vs. low) & $1.54(1.14-2.08)$ & 0.005 & $1.37(1.03-1.83)$ & 0.031 \\
\hline & Plk4 (high vs. low) & $0.50(0.36-0.68)$ & $8.67 \times 10^{-6}$ & $0.67(0.5-0.9)$ & 0.007 \\
\hline \multirow[t]{4}{*}{ Adj.Chemo } & Plk1 (high vs. low) & $0.64(0.43-0.98)$ & 0.039 & $0.45(0.28-0.72)$ & 0.0009 \\
\hline & Plk2 (high vs. low) & $2.46(1.61-3.76)$ & $3.27 \times 10^{-5}$ & $2.07(1.31-3.29)$ & 0.002 \\
\hline & Plk3 (high vs. low) & $1.26(0.83-1.9)$ & 0.28 & $1.5(0.95-2.37)$ & 0.085 \\
\hline & Plk4 (high vs. low) & $0.68(0.45-1.03)$ & 0.066 & $0.72(0.46-1.13)$ & 0.156 \\
\hline
\end{tabular}

Plk, polo-like kinase 2; Adj.Chemo. with adjuvant chemotherapy; DFS, disease-free survival; OS, overall survival; HR, hazard ratio; CI, confidence interval.

knockdown exhibited increased apoptosis, compared with the scramble control cells in DMSO. Oxaliplatin treatment $(4 \mu \mathrm{M}$ for $16 \mathrm{~h}$ ) induced apoptosis to a higher level, compared with that in the DMSO control in the Plk2-knockdown cells. By contrast, oxaliplatin only induced minor apoptosis over DMSO treatment in the scramble control Colo-678 cells (Fig. 4F and G).
Subsequently, the effect of the overexpression of Plk2 on chemosensitivity was examined in CRC cells. The Plk2-overexpressing SW620 cells had an increased $\mathrm{IC}_{50}$ to oxaliplatin (Plk2, vs. vector, $3.39 \mu \mathrm{M}, 95 \% \mathrm{CI}$ : 2.97-3.88, vs. $1.08 \mu \mathrm{M}, 95 \% \mathrm{CI}: 0.94-1.24)$, and were more resistant to $5-\mathrm{Fu}$ (Plk2, vs. vector, $\mathrm{IC}_{50}, 12.92 \mu \mathrm{M}$, 


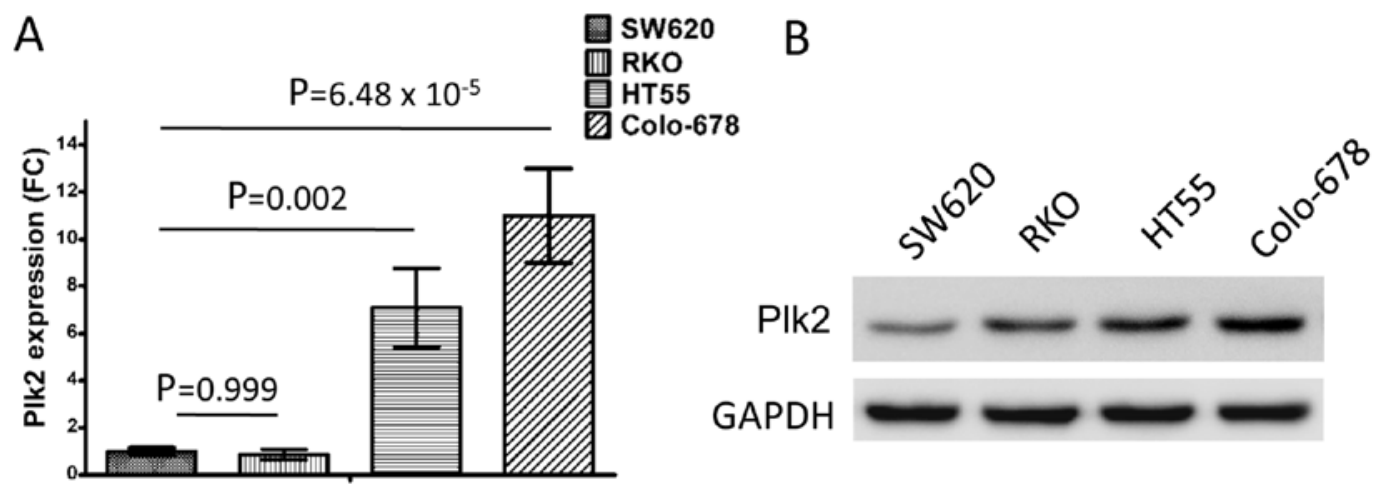

C

- Colo-678, IC $50(95 \% \mathrm{Cl}): 26.4(24.1-28.91)$

D

- SW620, IC $\mathrm{C}_{50}(95 \% \mathrm{Cl}): 1.22(1.07-1.4)$

ه HT55, IC $\mathrm{I}_{50}(95 \% \mathrm{Cl}): 7.32(6.5-8.25)$

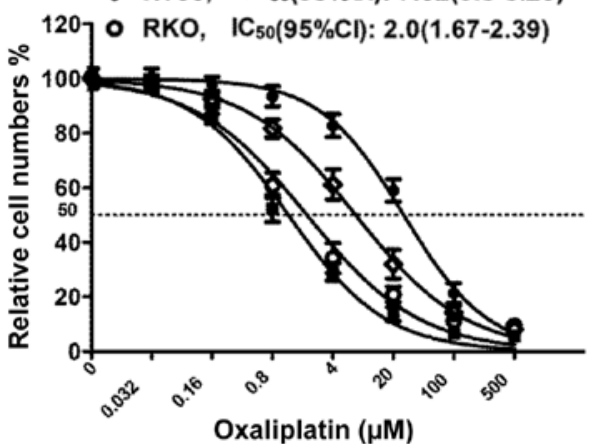

D Colo-678, IC $50(95 \% \mathrm{Cl}): 54.81(46.36-64.8)$

- SW620, IC $\mathrm{C}_{50}(95 \% \mathrm{Cl}): 5.55(4.68-6.58)$

- HT55, IC IC $50(95 \% \mathrm{Cl}): 38.85(32.51-46.42)$

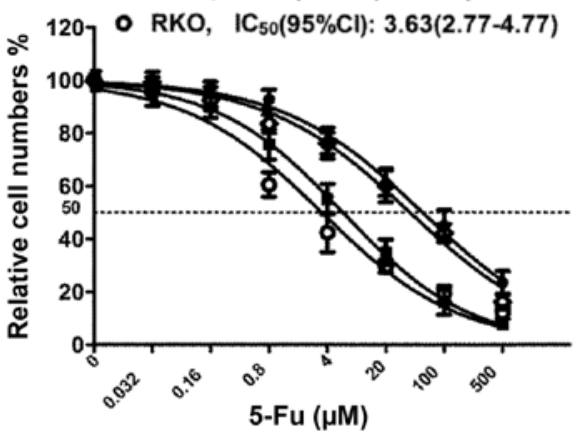

$E$

CCLE database

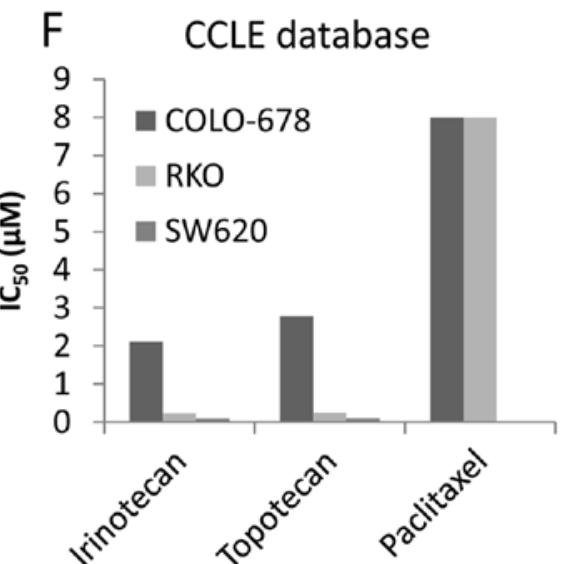

Figure 3. Correlation between the expression of Plk2 and chemosensitivity in CRC cell lines. (A) Gene expression of Plk2 in four CRC cell lines by RT-qPCR analysis. Relative expression (FC) of Plk2was calculated with GAPDH as a reference gene, and normalized to that of SW620 cells. Data are presented as the mean \pm standard deviation from three independent experiments, with triplicate amplifications for each experiment. The overall difference in the expression of Plk2 among the four cell lines was calculated using one-way analysis variance $\left(\mathrm{P}=2.82 \times 10^{-5}\right)$. Multiple comparisons were calculated by Tukey's 'Honest Significant Difference' method. The P-value of multiple comparisons between SW620 and other three cells is shown. (B) Western blot analysis of protein levels of Plk2 in the four CRC cell lines. GAPDH shows equal sample loading. Dose-response to (C) oxaliplatin and (D) 5-Fu in the four CRC cell lines. Cells were treated with DMSO or different concentrations of chemotherapeutic drugs for $72 \mathrm{~h}$. The viable cell number was determined by cell viability assay. Data is plotted as the mean \pm standard deviation of three independent experiments with six repeats for each experiment. (E) Gene expression of Plk2 in four CRC cell lines, determined by a microarray from the CCLE database. Relative expression (FC) of Plk2 was normalized to that of SW620 cells. (F) Pharmacological data of three CRC cells from CCLE database. $\mathrm{IC}_{50}$ values of three chemotherapeutic drugs for different CRC cell lines are presented. Plk2, polo-like kinase 2; RT-qPCR, reverse transcription-quantitative polymerase chain reaction; CRC, colorectal carcinoma; FC, fold change; CCLE, Cancer Cell Line Encyclopedia; $\mathrm{IC}_{50}$, half maximal inhibitory concentration.

95\% CI: $11.21-14.89$, vs. $5.13 \mu \mathrm{M}, 95 \%$ CI: 4.49-5.86), as shown in Fig. 5A and B. Similar results were observed for RKO cells with exogenous overexpression of Plk2 (Fig. $5 \mathrm{C}, \mathrm{IC}_{50}$ to oxaliplatin, Plk2, vs. vector, $4.82 \mu \mathrm{M}, 95 \%$ CI: 4.23-5.49, vs. $1.64 \mu \mathrm{M}, 95 \%$ CI: 1.41-1.9). The results of the western blot analysis confirmed the overexpression of Plk2 protein in the
Plk2-transfected cells, compared with that in the vector control cells (Fig. 5D). As expected, following treatment with $1 \mu \mathrm{M}$ oxaliplatin for $16 \mathrm{~h}$, the control cells exhibited increased the levels of cleaved PARP (Fig. 5E). However, the overexpression of Plk2 in SW620 cells inhibited the upregulation of cleaved PARP in response to oxaliplatin (Fig. 5E). Flow cytometric 

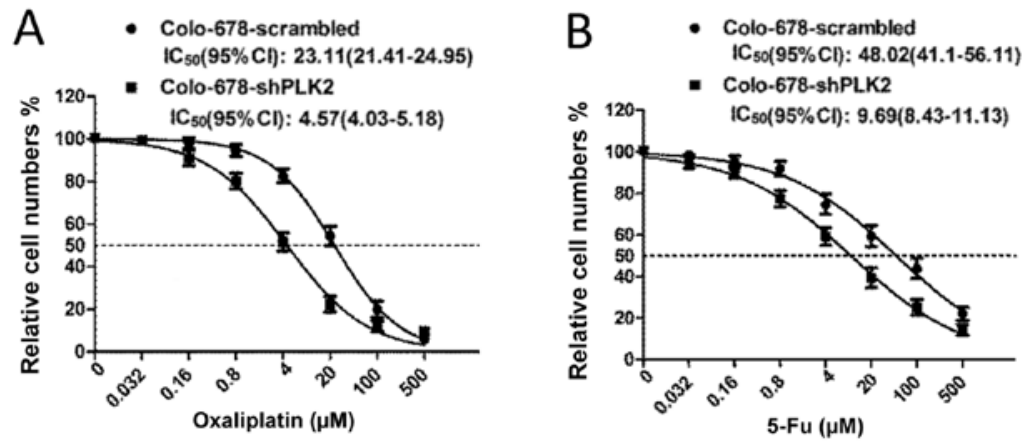

D

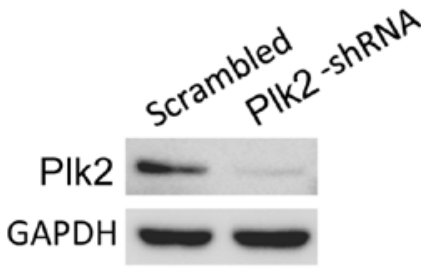

Colo-678

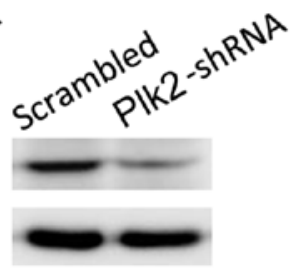

HT55
$\mathrm{F}$
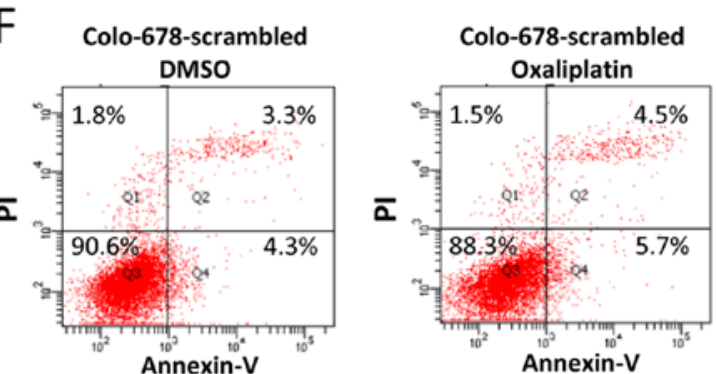

Colo-678-PIk2-shRNA
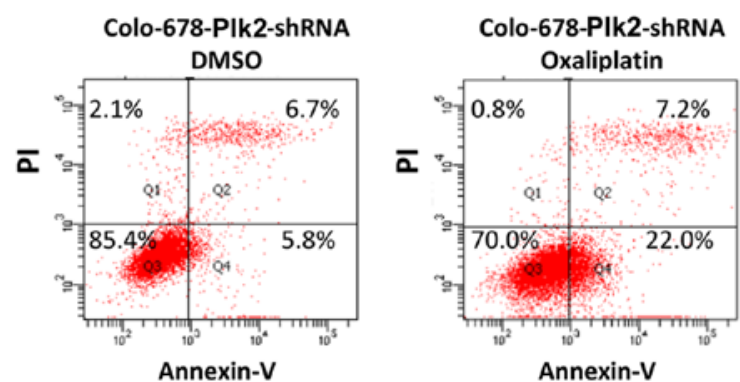

$E$

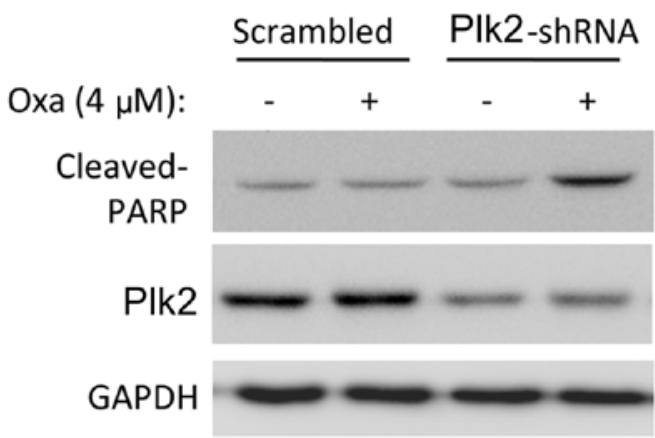

G

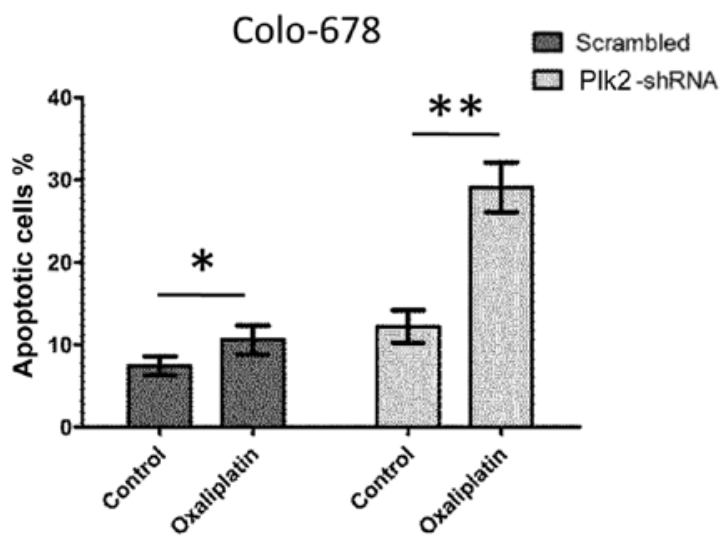

Figure 4. Effect of Plk2 knockdown on chemosensitivity and apoptosis of CRC cells. Dose-response of chemotherapeautic agents on the growth effect of CRC cells transfected with Plk2-shRNA and scrambled control. Colo-6678 cells were treated with DMSO or different concentrations of (A) oxaliplatin or (B) 5-Fu for $72 \mathrm{~h}$. HT-55 cells were treated with different concentrations of (C) oxaliplatin. The viable cell number was determined using an MTT assay. Data are plotted as the mean \pm standard deviation of three independent experiments with six repeats for each experiment. (D) Western blot analysis indicated the knocked down expression of Plk2, with GAPDH as an endogenous control. Effect of Plk2 knockdown on apoptosis. Cells infected with lentiviruses encoding Plk2-targeting or scrambled shRNAs were treated with oxaliplatin $(4 \mu \mathrm{M})$ or DMSO for $16 \mathrm{~h}$. (E) Cell lysates were subjected to western blot analysis for cleaved PARP. (F) Cells were stained with Annexin V and PI and analyzed using flow cytometry. (G) Apoptotic cell rates are shown as a bar plot. Data are representative of three independent experiments. The P-value was calculated using Student's t-test (unpaired). ${ }^{*} \mathrm{P}<0.05 ;{ }^{* *} \mathrm{P}<0.01$. CRC, colorectal carcinoma; Plk2, polo-like kinase 2; PARP, poly(ADP-ribose) polymerase 1; shRNA, short hairpin RNA; 5-Fu, fluorouracil; DMSO, dimethyl sulfoxide; PI, propidiumiodide; IC 50 , half maximal inhibitory concentration.

analysis demonstrated that the Plk2-overexpressing SW620 cells exhibited decreased apoptosis, compared with the vector control cells in the DMSO and oxaliplatin treatment conditions. Oxaliplatin treatment $(1 \mu \mathrm{M}$ for $16 \mathrm{~h})$ induced a higher level of apoptosis in the vector control cells, compared with the DMSO control cells. However, oxaliplatin induced only minor apoptosis in the Plk2-overexpressing SW620 cells over DMSO treatment (Fig. 5F and G).

\section{Discussion}

In the present study, the clinical association of Plk2 in patients with CRC was examined and its role in chemoresistance in CRC cells was investigated. A higher expression of Plk2 was more frequently observed in proximally located tumors, and was correlated with pMMR status, BRAF mutation, KRAS mutation and TP53 wild-type. The expression ofPlk2 was a 

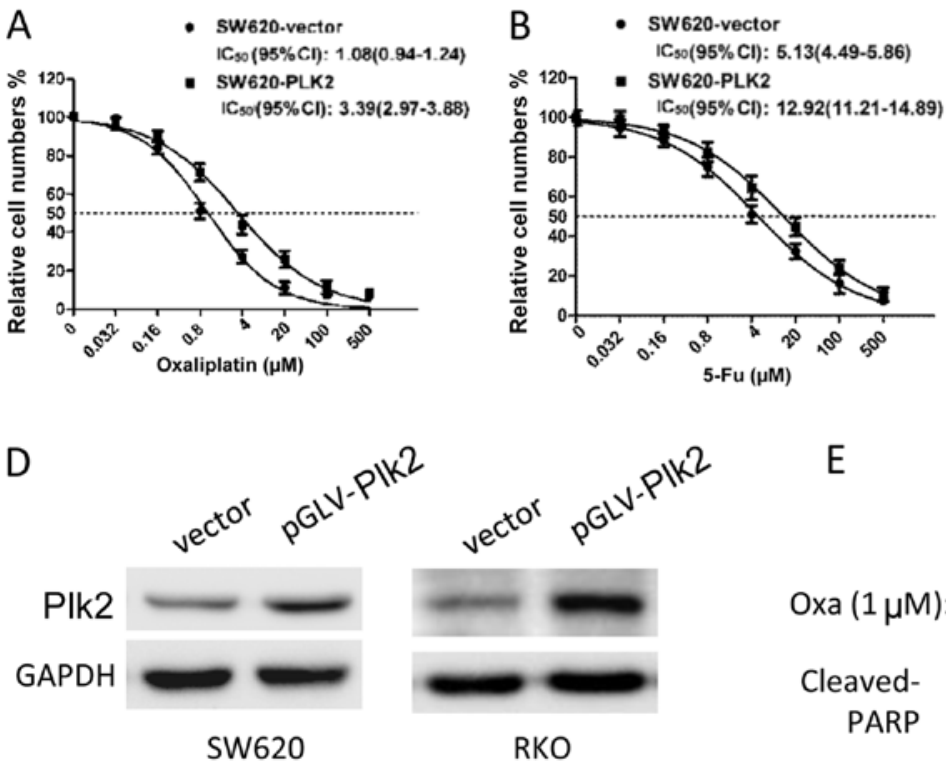

F

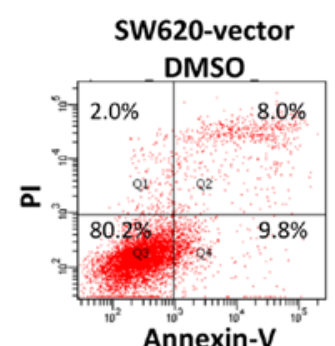

Annexin-V

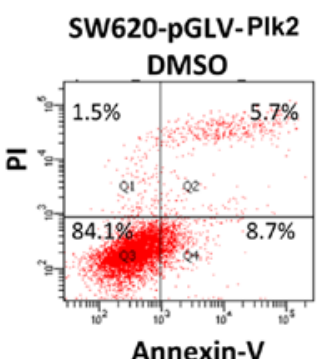

Annexin-V

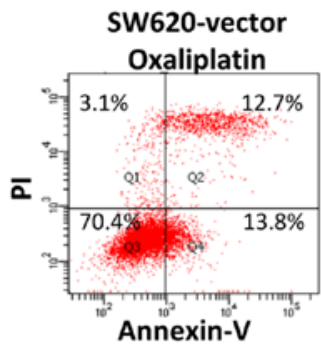

SW620-pGLV-PIk2

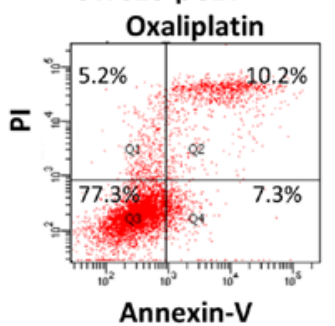

G
E

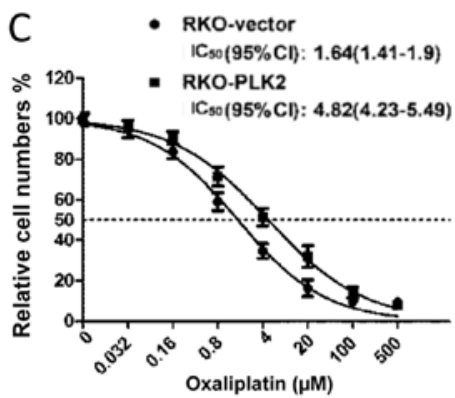

SW620
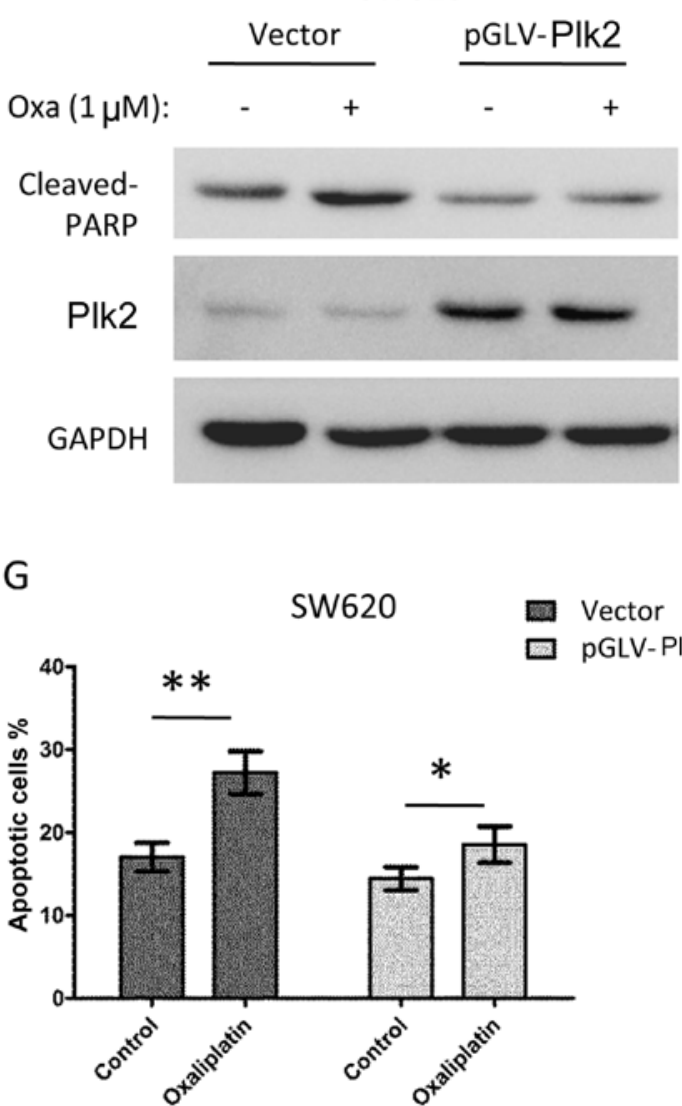

Figure 5. Effect of the overexpression of Plk2 on chemosensitivity and apoptosis of CRC cells. Dose-response of chemotherapeutic agents on the growth effect of Plk2 and vector control CRC cells. Colo-678 cells were treated with DMSO or different concentration of (A) oxaliplatin or (B) 5-Fu for 72 h. HT-55 cells were treated with DMSO or different concentration of (C) oxaliplatin. The viable cell number was determined using an MTT assay. Data are plotted as the mean \pm standard deviation of three independent experiments with six repeats for each experiment. (D) Western blot indicating the overexpression of Plk2, with GAPDH as endogenous control. Effects of the overexpression of Plk2 on apoptosis were examined. Cells infected with lentiviruses encoding Plk2 or vector control were treated with oxaliplatin $(1 \mu \mathrm{M})$ or DMSO for $16 \mathrm{~h}$. (E) Cell lysates were subjected to western blot analysis for cleaved PARP. (F) Cells were stained with Annexin V and PI, and analyzed using flow cytometry. (G) Apoptotic cell rates are shown as a bar plot. Data are representative of three independent experiments. The P-value was calculated using Student's t-test (unpaired). ${ }^{*} \mathrm{P}<0.05 ;{ }^{* *} \mathrm{P}<0.01$. CRC, colorectal carcinoma; Plk2, polo-like kinase 2; PARP, poly(ADP-ribose) polymerase 1; shRNA; 5-Fu, fluorouracil; DMSO, dimethyl sulfoxide; PI, propidium iodide; $\mathrm{IC}_{50}$, half maximal inhibitory concentration.

prognostic factor for an unfavorable outcome in patients who received adjuvant chemotherapy, but not in those without. The higher expression of Plk2 was correlated with increased resistance to chemotherapeutic agents in CRC cells. The knockdown of Plk2 in cells expressing a high level of Plk2 resulted in enhanced apoptosis and sensitized cells to chemotherapeutic drugs. By contrast, the exogenous expression of Plk2 in cells expressing a low level of Plk2 inhibited the apoptosis induced by chemotherapeutic agents. These results suggested that Plk2 may be involved in chemoresistance in CRC through inhibiting apoptosis.
Plk2 has been documented as a tumor suppressor in B-cell lymphoma and ovarian cancer, and is transcriptionally silenced in these tumors as a result $(17,18)$. However, another study demonstrated that Plk2 was significantly overexpressed in CRC tissues (24); elevated protein levels of Plk2 were associated with tumor metastasis and poor prognosis for OS and DFS (24). Consistently, the results of the present study showed that a higher gene expression of Plk2 in CRC was associated with shorter OS and DFS of patients. It was also revealed that a higher expression of Plk2 was more likely to be associated with proximally located tumors, which are reported to have 
poorer clinical outcome, compared with distal tumors $(28,29)$. The present study found that Plk2 was only of prognostic value in the patients who received adjuvant chemotherapy, but not in those without adjuvant chemotherapy. However, this finding was not reported in the previous studies. Multivariate Cox regression revealed that the expression of Plk 2 wasan independent prognostic factor for OS and DFS in patients who received adjuvant chemotherapy. In III/IV stage CRC, adjuvant chemotherapy significantly improved the OS of patients. However, the improvement of OS by adjuvant chemotherapy was observed only in the Plk2-low subgroup and not in the Plk2-high subgroup. For stage I/II CRC, the expression of Plk2 was not able to predict patient outcome in patients, whether they received adjuvant chemotherapy or not (data not shown). This was possibly due to only a small number of patients at the early stage $(n=55)$ receiving adjuvant chemotherapy. These findings suggested that Plk2 serves as a promising biomarker for predicting the outcome benefit from adjuvant chemotherapy in late stage CRC.

The Plk family is essential in cell cycle checkpoint and DNA damage signaling (15). Four of the family members (Plk1-4) were present in the CRC dataset analyzed in the present study. Further investigation found that high expression levels of Plk1 and Plk4 were protective factors for favorable prognosis, whereas the overexpression of Plk2 and Plk3 was associated with unfavorable patient outcome (Table IV). Additionally, for patients who received adjuvant chemotherapy, only Plk1 and Plk2 significantly affected the prediction of DFS and OS (Table IV). These findings suggested that the Plk family members may have different roles in the carcinogenesis of CRC.

$\mathrm{dMMR}$ is a common genetic alteration in CRCs. A previous study demonstrated that dMMR tumors were resistant to 5-Fu-based therapy and that the patients benefitted less from adjuvant chemotherapy (7). The results of the present study indicated that the tumors with a higher expression of Plk2 had a higher frequency of dMMR (21.2\%), compared with those with a lower expression of Plk2 (5.3\%). It has been reported that the BRAF mutation is associated with dMMR status in CRC $(10,30)$. Accordingly, the present study found that the upregulation of Plk2 was associated with a higher frequency of BRAF mutation, compared with the low expression of Plk2 (15.2 vs. 2.8\%, respectively). Although the KRAS mutation is almost exclusive to the BRAF mutation in CRC $(9,10)$, the present study found that the expression of Plk2 was also positively correlated with the KRAS mutation rate (Plk2-high vs. low: 44.5 vs. $32.2 \%$ ). These findings suggested that the upregulation of Plk2 may be more likely to be observed in CRC with oncogenic mutations. In addition, according to previous reports, dMMR, BRAF and KRAS mutations are more frequently detected in proximal/rightsided tumors $(9,10)$. Consistently, the present study revealed that the proximally located tumors were associated with a higher expression of Plk2. In addition, the TP53 mutation was inversely correlated with the expression ofPlk2, which may due to the expression of Plk2 being induced by wildtype TP53 $(31,32)$. From the GDSC database (33), the present study found that TP53 was mutated in SW620 and HT55 cells, KRAS mutations were found in SW620 and Colo-678 cells, and BRAF mutations were observed in RKO cells. Therefore, there was no marked correlation between the chemosensitivity and the mutant status of TP53, KRAS and BRAF in the four CRC cells.

A previous study demonstrated that a high expression of Plk2 was associated with an anti-apoptotic effect in CRC cells under normal tissue culture conditions (24). However, the downregulation of Plk2 mediated by microRNA-27b has been shown to be associated with accelerated proliferation and inhibited paclitaxel-induced cell apoptosis in cervical cancer (19). These results suggest that Plk2 may have bidirectional effects in the regulation of apoptosis based on different cell types. In the present study, it was found that a higher expression of Plk2 indicated a poorer outcome in patients with CRC who received adjuvant chemotherapy, suggesting an anti-chemotherapeutic effect of Plk2. A higher expression level of Plk2 was observed in CRC cells with increased resistance to chemothereapeutic agents. In line with previous results (24), the present study observed that the knockdown of Plk2 in Colo-678 cells resulted in increased apoptosis, whereas the exogenous expression of Plk2 decreased apoptosis in SW620 cells. It was also found that Plk2 was important in the response of CRC cells to chemotherapeutic agents. Apoptosis induced by oxaliplatin was markedly enhanced in the cells with depressed expression of Plk2. The observation of decreased apoptosis induced by oxaliplatin in Plk2-overexpressing cells confirmed the chemoresistant feature of Plk2. Taken together, these data suggested that a high expression of Plk 2 may contribute to chemoresistance by inhibiting the apoptosis of CRC cells.

There were several possible mechanisms underlying the anti-chemotherapeutic role of Plk2. The expression of Plk2 is transcriptionally regulated by TP53, and is involved in DNA replication and the S-phase checkpoint $(21,31)$. Plk2 depletion deficiency results in enhanced phosphorylation of $\mathrm{H} 2 \mathrm{AX}$ and DNA damage in response to replication stress (21). The mutant TP53 can be phosphorylated by Plk2, to result in an improved oncogenic effect and enhanced chemoresistance in cancer cells (34). However, the TP53 mutation was identified in the chemoresistant HT-55 cells and the sensitive SW620 cells, suggesting other mechanisms are involved in the chemoresistant effect of Plk2.TAp73 is a known tumor suppressor with a similar structure top 53. The function of TAp73 can be inhibited by Plk2, which phosphorylates TAp73 at Ser48 and prevents its nuclear translocation (22). Suppressing the expression of Plk2 enhances DNA-damaging drug induced apoptosis through a TAp73-dependent manner (22). In addition, previous studies have found that TAp73 is involved in the drug-induced apoptosis of CRC cells $(35,36)$, particularly in p53-deficient cells (35). Another downstream target of Plk2 is F-box and WD repeat domain containing 7 (Fbxw7). It is reported that Plk2 binds to Fbxw7 and mediates its subsequent degradation, resulting an in anti-apoptotic effect in CRC cells (24). Accordingly, a low expression of Fbxw7 was associated with poor patient prognosis and increased resistance to chemotherapy (37). Collectively, these previous results indicated that TAp73 and Fbxw7 may serve as the important downstream targets of Plk2 in the chemoresistance of CRC cells.

In conclusion, the present study found that a high expression of Plk2 was significantly associated with reduced benefit from adjuvant chemotherapy in late stage CRC. Furthermore, experiments involving the knockdown and exogenous 
overexpression of Plk2 demonstrated that Plk2 is important in the chemoresistance of CRC cells. These results suggest that Plk2 may serve as a predictor marker for the clinical benefit of adjuvant chemotherapy, and that targeting Plk2 offers a promising novel strategy in CRC therapy.

\section{Acknowledgements}

Not applicable.

\section{Funding}

No funding was received.

\section{Availability of data and materials}

The datasets analyzed in the present study are publicly available in Gene Expression Omnibus (accession nos. GSE39582 and GSE36133).

\section{Authors' contributions}

The contributions of the authors were as follows: Conception and design: JC; development of methodology: YX, YL and QL; acquisition of data: YX, YL and QL; analysis and interpretation of data: YX and YL; writing, review, and/or revision of the manuscript: YX and JC; administrative, technical or material support: JC and QL; study supervision: YX and YL. All authors read and approved the final manuscript.

\section{Ethics approval and consent to participate}

Not applicable.

\section{Consent for publication}

Not applicable.

\section{Competing interests}

The authors declare that there have no competing interests.

\section{References}

1. Siegel RL, Miller KD and Jemal A: Cancer Statistics, 2017. CA Cancer J Clin 67: 7-30, 2017.

2. Siegel RL, Miller KD, Fedewa SA, Ahnen DJ, Meester RGS, Barzi A and Jemal A: Colorectal cancer statistics, 2017. CA Cancer J Clin 67: 177-193, 2017.

3. André T, Boni C, Mounedji-Boudiaf L, Navarro M, Tabernero J, Hickish T, Topham C, Zaninelli M, Clingan P, Bridgewater J, et al; Multicenter International Study of Oxaliplatin/5-Fluorouracil/ Leucovorin in the Adjuvant Treatment of Colon Cancer (MOSAIC) Investigators: Oxaliplatin, fluorouracil, and leucovorin as adjuvant treatment for colon cancer. N Engl J Med 350: 2343-2351, 2004.

4. André T, de Gramont A, Vernerey D, Chibaudel B, Bonnetain F, Tijeras-Raballand A, Scriva A, Hickish T, Tabernero J, Van Laethem JL, et al: Adjuvant fluorouracil, leucovorin, and oxaliplatin in stage II to III colon cancer: Updated 10-year survival and outcomes according to BRAF mutation and mismatch repair status of the MOSAIC study. J Clin Oncol 33: 4176-4187, 2015.

5. Gray R, Barnwell J, McConkey C, Hills RK, Williams NS and Kerr DJ; Quasar Collaborative Group: Adjuvant chemotherapy versus observation in patients with colorectal cancer: A randomised study. Lancet 370: 2020-2029, 2007.
6. Cao B, Luo L, Feng L, Ma S, Chen T, Ren Y, Zha X, Cheng S, Zhang K and Chen C: A network-based predictive gene-expression signature for adjuvant chemotherapy benefit in stage II colorectal cancer. BMC Cancer 17: 844, 2017.

7. Sargent DJ, Marsoni S, Monges G, Thibodeau SN, Labianca R, Hamilton SR, French AJ, Kabat B, Foster NR, Torri V, et al: Defective mismatch repair as a predictive marker for lack of efficacy of fluorouracil-based adjuvant therapy in colon cancer. J Clin Oncol 28: 3219-3226, 2010.

8. Ribic CM, Sargent DJ, Moore MJ, Thibodeau SN, French AJ, Goldberg RM, Hamilton SR, Laurent-Puig P, Gryfe R, Shepherd LE, et al: Tumor microsatellite-instability status as a predictor of benefit from fluorouracil-based adjuvant chemotherapy for colon cancer. N Engl J Med 349: 247-257, 2003.

9. Gonsalves WI, Mahoney MR, Sargent DJ, Nelson GD, Alberts SR, Sinicrope FA, Goldberg RM, Limburg PJ, Thibodeau SN, Grothey A, et al: Patient and tumor characteristics and BRAF and KRAS mutations in colon cancer, NCCTG/Alliance N0147. J Natl Cancer Inst: Jun 12, 2014 (Epub ahead of print). doi: 10.1093/jnci/dju106..

10. Li W, Qiu T, Zhi W, Shi S, Zou S, Ling Y, Shan L, Ying J and Lu N: Colorectal carcinomas with KRAS codon 12 mutation are associated with more advanced tumor stages. BMC Cancer 15: $340,2015$.

11. Hutchins G, Southward K, Handley K, Magill L, Beaumont C, Stahlschmidt J, Richman S, Chambers P, Seymour M, Kerr D, et al: Value of mismatch repair, KRAS, and BRAF mutations in predicting recurrence and benefits from chemotherapy in colorectal cancer. J Clin Oncol 29: 1261-1270, 2011.

12. Sinicrope FA, Mahoney MR, Smyrk TC, Thibodeau SN Warren RS, Bertagnolli MM, Nelson GD, Goldberg RM, Sargent DJ and Alberts SR: Prognostic impact of deficient DNA mismatch repair in patients with stage III colon cancer from a randomized trial of FOLFOX-based adjuvant chemotherapy. J Clin Oncol 31: 3664-3672, 2013.

13. Yurgelun MB, Kulke MH, Fuchs CS, Allen BA, Uno H, Hornick JL, Ukaegbu CI, Brais LK, McNamara PG, Mayer RJ, et al: Cancer susceptibility gene mutations in individuals with colorectal cancer. J Clin Oncol 35: 1086-1095, 2017.

14. Vakiani E, Janakiraman M, Shen R, Sinha R, Zeng Z, Shia J, Cercek A, Kemeny N, D'Angelica M, Viale A, et al: Comparative genomic analysis of primary versus metastatic colorectal carcinomas. J Clin Oncol 30: 2956-2962, 2012.

15. Reinhardt HC and Yaffe MB: Phospho-Ser/Thr-binding domains: Navigating the cell cycle and DNA damage response. Nat Rev Mol Cell Biol 14: 563-580, 2013.

16. Takai N, Hamanaka R, Yoshimatsu J and Miyakawa I: Polo-like kinases (Plks) and cancer. Oncogene 24: 287-291, 2005.

17. Syed N, Coley HM, Sehouli J, Koensgen D, Mustea A, Szlosarek P, McNeish I, Blagden SP, Schmid P, Lovell DP, et al: Polo-like kinase Plk2 is an epigenetic determinant of chemosensitivity and clinical outcomes in ovarian cancer. Cancer Res 71: 3317-3327, 2011.

18. Syed N, Smith P, Sullivan A, Spender LC, Dyer M, Karran L, O'Nions J, Allday M,Hoffmann I,Crawford D, et al: Transcriptional silencing of Polo-like kinase 2 (SNK/PLK2) is a frequent event in B-cell malignancies. Blood 107: 250-256, 2006.

19. Liu F, Zhang S, Zhao Z, Mao X, Huang J, Wu Z, Zheng L and Wang Q: MicroRNA-27b up-regulated by human papillomavirus 16 E7 promotes proliferation and suppresses apoptosis by targeting polo-like kinase 2 in cervical cancer. Oncotarget 7: 19666-19679, 2016.

20. Gee HE, Buffa FM, Harris AL, Toohey JM, Carroll SL, Cooper CL, Beith J, McNeil C, Carmalt H, Mak C, et al: MicroRNA-related DNA repair/cell-cycle genes independently associated with relapse after radiation therapy for early breast cancer. Int J Radiat Oncol Biol Phys 93: 1104-1114, 2015.

21. Matthew EM, Yen TJ, Dicker DT, Dorsey JF, Yang W, Navaraj A and El-Deiry WS: Replication stress, defective S-phase checkpoint and increased death in Plk2-deficient human cancer cells. Cell Cycle 6: 2571-2578, 2007.

22. Hu Z, Xu Z, Liao X, Yang X, Dong C, Luk K, Jin A and Lu H: Polo-like kinase 2 acting as a promoter in human tumor cells with an abundance of TAp73. Onco Targets Ther 8: 3475-3488, 2015.

23. Li J, Ma W, Wang PY, Hurley PJ, Bunz F and Hwang PM: Polo-like kinase 2 activates an antioxidant pathway to promote the survival of cells with mitochondrial dysfunction. Free Radic Biol Med 73: 270-277, 2014. 
24. Ou B, Zhao J, Guan S, Wangpu X, Zhu C, Zong Y, Ma J, Sun J, Zheng M, Feng H, et al: Plk2 promotes tumor growth and inhibits apoptosis by targeting Fbxw7/Cyclin E in colorectal cancer. Cancer Lett 380: 457-466, 2016.

25. Marisa L, de Reyniès A, Duval A, Selves J, Gaub MP, Vescovo L, Etienne-Grimaldi MC, Schiappa R, Guenot D, Ayadi M, et al: Gene expression classification of colon cancer into molecular subtypes: Characterization, validation, and prognostic value. PLoS Med 10: e1001453, 2013.

26. Barretina J,Caponigro G, Stransky N, Venkatesan K, Margolin AA, Kim S, Wilson CJ, Lehár J, Kryukov GV, Sonkin D, et al: The cancer cell line encyclopedia enables predictive modelling of anticancer drug sensitivity. Nature 483: 603-607, 2012.

27. Livak KJ and Schmittgen TD: Analysis of relative gene expression data using real-time quantitative PCR and the 2(-Delta Delta C(T)) method. Methods 25: 402-408, 2001.

28. Wong HL, Lee B, Field K, Lomax A, Tacey M, Shapiro J, McKendrick J, Zimet A, Yip D, Nott L, et al: Impact of primary tumor site on bevacizumab efficacy in metastatic colorectal cancer. Clin Colorectal Cancer 15: e9-e15, 2016.

29. Perron L, Daigle JM, Vandal N, Guertin MH and Brisson J: Characteristics affecting survival after locally advanced colorectal cancer in Quebec. Curr Oncol 22: e485-e492, 2015.

30. Li W, Zhi W, Zou S, Qiu T, Ling Y, Shan L, Shi S and Ying J: Distinct clinicopathological patterns of mismatch repair status in colorectal cancer stratified by KRAS mutations. PLoS One 10: e0128202, 2015.

31. Burns TF, Fei P, Scata KA, Dicker DT and El-Deiry WS: Silencing of the novel p53 target gene Snk/Plk2 leads to mitotic catastrophe in paclitaxel (taxol)-exposed cells. Mol Cell Biol 23 5556-5571, 2003.
32. Shimizu-Yoshida Y, Sugiyama K, Rogounovitch T, Ohtsuru A, Namba H, Saenko V and Yamashita S: Radiation-inducible hSNK gene is transcriptionally regulated by 533 binding homology element in human thyroid cells. Biochem Biophys Res Commun 289: 491-498, 2001.

33. Yang W, Soares J, Greninger P, Edelman EJ, Lightfoot $H$, Forbes S, Bindal N, Beare D, Smith JA, Thompson IR, et al: Genomics of drug sensitivity in cancer (GDSC): A resource for therapeutic biomarker discovery in cancer cells. Nucleic Acids Res 41: D955-D961, 2013.

34. Valenti F, Fausti F, Biagioni F, Shay T, Fontemaggi G, Domany E, Yaffe MB, Strano S, Blandino G and Di Agostino S: Mutant p53 oncogenic functions are sustained by Plk2 kinase through an autoregulatory feedback loop. Cell Cycle 10: 4330-4340, 2011.

35. Dabiri Y, Kalman S, Gürth CM, Kim JY, Mayer V and Cheng X: The essential role of TAp73 in bortezomib-induced apoptosis in p53-deficient colorectal cancer cells. Sci Rep 7: 5423, 2017.

36. Herreros-Villanueva M, Muñiz P, García-Girón C, Cavia-Saiz M and del Corral MJ: TAp73 is one of the genes responsible for the lack of response to chemotherapy depending on B-Raf mutational status. J Transl Med 8: 15, 2010

37. Lorenzi F, Babaei-Jadidi R, Sheard J, Spencer-Dene B and Nateri AS: Fbxw7-associated drug resistance is reversed by induction of terminal differentiation in murine intestinal organoid culture. Mol Ther Methods Clin Dev 3: 16024, 2016.

(i) $($ ) This work is licensed under a Creative Commons Attribution-NonCommercial-NoDerivatives 4.0 International (CC BY-NC-ND 4.0) License. 